\title{
Follow-up studies of anorexia nervosa: a review of four decades of outcome research
}

\author{
Steinhausen, H-C ; Rauss-Mason, C ; Seidel, R
}

\begin{abstract}
In 1983 we presented a systematic analysis of the available literature on the course of anorexia nervosa (Steinhausen Glanville, 1983 a). The survey was based on 45 English and German language studies published between 1953 and 1981. During the past decade there has been a striking increase of publications related to eating disorders in general. This pertains as well to follow-up studies on anorexia nervosa. In addition to studies compiled in our previous report, we were able to locate another 22 follow-up studies published in major English and German language journals between 1981 and 1989
\end{abstract}

DOI: https://doi.org/10.1017/s0033291700020559

Posted at the Zurich Open Repository and Archive, University of Zurich ZORA URL: https://doi.org/10.5167/uzh-155308

Journal Article

Published Version

Originally published at:

Steinhausen, H-C; Rauss-Mason, C; Seidel, R (1991). Follow-up studies of anorexia nervosa: a review of four decades of outcome research. Psychological Medicine, 21(02):447.

DOI: https://doi.org/10.1017/s0033291700020559 


\title{
Follow-up studies of anorexia nervosa: a review of four decades of outcome research
}

\author{
H.-CH. STEINHAUSEN, ${ }^{1}$ C. RAUSS-MASON AND R. SEIDEL \\ From the Department of Child and Adolescent Psychiatry, University of Zürich, Switzerland
}

\section{INTRODUCTION}

In 1983 we presented a systematic analysis of the available literature on the course of anorexia nervosa (Steinhausen \& Glanville, 1983a). The survey was based on 45 English and German language studies published between 1953 and 1981. During the past decade there has been a striking increase of publications related to eating disorders in general. This pertains as well to follow-up studies on anorexia nervosa. In addition to studies compiled in our previous report, we were able to locate another 22 followup studies published in major English and German language journals between 1981 and 1989.

The aim of the present reappraisal is twofold, namely, $(a)$ to summarize the findings coming from publications of the last decade and $(b)$ to compare the results with those coming from our previous survey. Accordingly, the findings of outcome-research of the 1980s will be compared with the findings of the 1950s-1970s in order to assess whether the course of anorexia nervosa has changed in the recent past, i.e. during the past decade. The question seems to be relevant insofar as there is considerable evidence that anorexia nervosa has become more common, or at least that it has been seen professionally more frequently in the recent past.

\section{GENERAL DESCRIPTION}

In comparison with 45 follow-up studies published between 1953 and 1981, there were 22 new studies on the same issue published in the remaining years of the 1980s. The sample characteristics of these more recent studies are

\footnotetext{
' Address for correspondence: Professor H.-Ch. Steinhausen, Department of Child and Adolescent Psychiatry, University of Zürich, Freiestrasse 15, CH-8028 Zürich, Switzerland.
}

shown in Table 1, which uses the same pattern of categorization as the previous survey (Steinhausen \& Glanville, 1983a). While the sample size of the 1950s-1970s studies range between 6 and 140, and range similarly between 11 and 151 for the early 1980s studies, the more recent studies tend to report on greater sample sizes. In general, there is only a small number of male patients in some of the studies.

The mean drop-out rate of the earlier studies was, however, only $11 \%$ (range $0-77$ ) and increased to $24 \%$ (range $0-27$ ) during the last decade. The relatively extensive samples of the more recent studies tend to have a considerable drop-out rate whereas the rather small series of patients described in the earlier studies suffered less from high attrition rates. A tentative preliminary conclusion that may be drawn concerns the decreased willingness of patients to be continuously monitored in follow-up studies.

A further differentiating trend of the more recent studies concerns the tendency to report on longer follow-ups. With the exception of the study by Theander (1985), this is not simply due to repeated reports on the same cohort of patients. On the contrary, it is quite remarkable that there are so many publications based on patients whose disease course had not previously been reported. However, most series are marked by a rather wide variation of duration of followup, as shown in Table 1. This implies that the evaluation of outcome may not be accurately derived from these studies due to the considerable differences in the duration of followup among the individual studies. Nevertheless, there is a strong tendency in the majority of the more recent studies to comply with Morgan and Russell's (1975) plea for a minimum follow-up period of four years.

It is quite difficult to compare the age-at-onset of the disease because the available data are not 


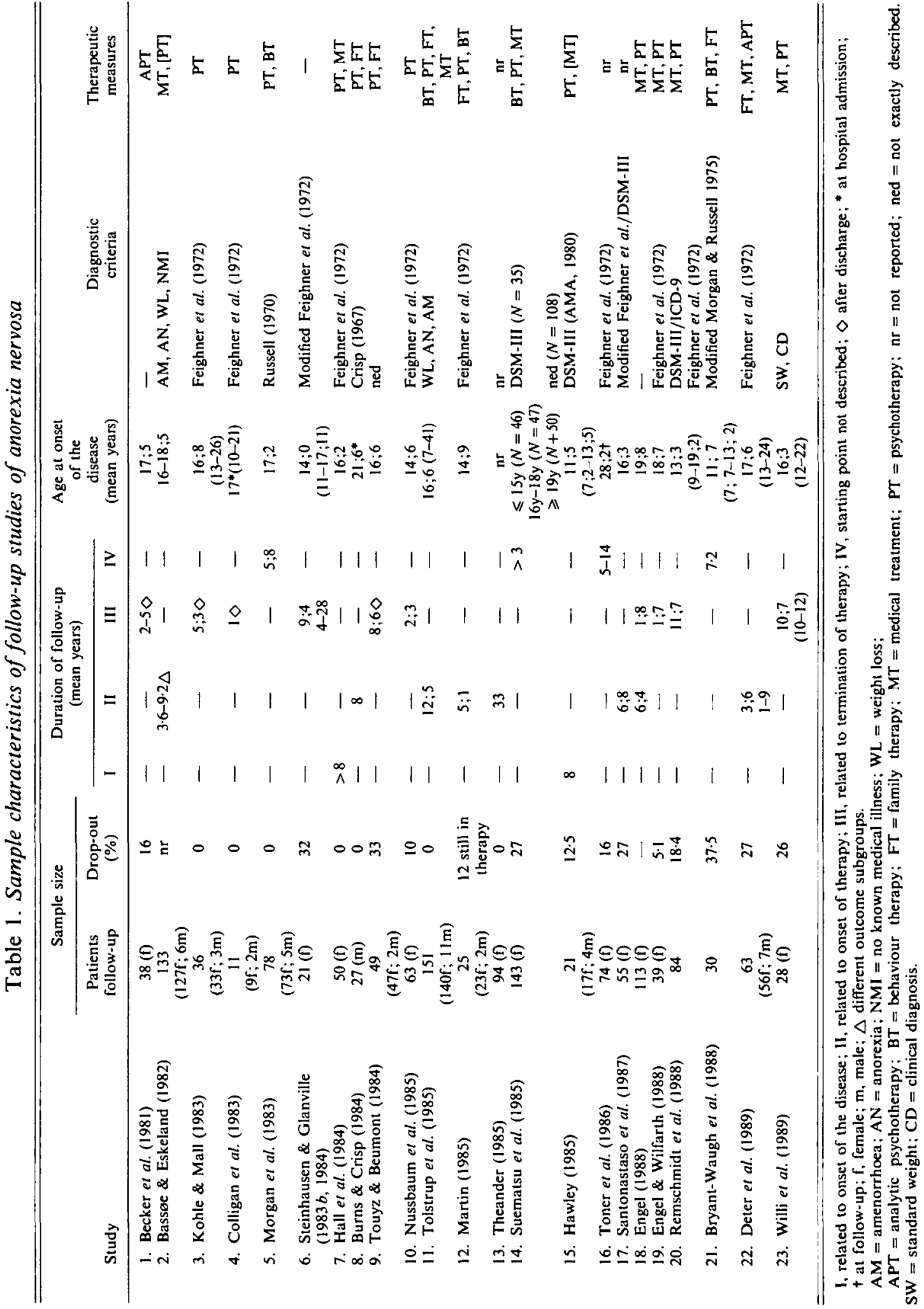


conducive to such definite comparison. There is no evidence that the typical age-at-onset during adolescence or early adulthood has changed, and the reports of patients with very early onset in recent studies are scarce. Furthermore, with regard to diagnostic criteria, there is still a remarkable preference for the criteria of Feighner et al. (1972), despite the fact that the DSM-III has influenced psychiatry considerably during the 1980s.

Treatment regimes in the majority of the more recent studies have been dominated by psychotherapy. While only a few series of patients have been treated solely with medical treatment or with psychoanalysis, there has been a growing tendency to include behaviour therapy and/or family therapy. Some series consisted of patients collected from different types of treatment settings, i.e. internal medicine, paediatrics, psychiatry, and adolescent psychiatry. Accordingly, differing treatment programmes were used among patients in the same follow-up study, making any comparison of treatment effects impossible. In addition, specification of treatment mode in these recent outcome studies is insufficient or lacking. The efficacy of specific treatment strategies for long-term outcome, therefore, cannot be evaluated from these recent studies.

\section{FOLLOW-UP RESULTS}

Unfortunately, methodological shortcomings (i.e. lack of controls or clinical contrast groups) and the varying measures of outcome used in the follow-up studies preclude use of any standardized meta-analysis technique. However, by using the same outline as the one used in our previous review (Steinhausen \& Glanville, $1983 \mathrm{~b}$ ), Table 2 allows a comparison of those earlier studies and the studies published in the 1980s. Accordingly, the literature on outcome of anorexia nervosa was screened for the following variables: the rate of normalization of weight, menstruation and eating behaviour, psychiatric status; indications of psychosocial adaptation; rates of chronicity and mortality; and global ratings of follow-up status.

As was noted about the earlier studies reported in our previous review, a significant number of the recent papers also neglect to report weight data. This is quite surprising considering that weight restoration is an important index for evaluating the course of anorexia nervosa. Taking these limitations into account, there is some evidence that data coming from the more recent studies are quite similar to the data originating from older studies. While the mean range of weight restored is $50-70 \%$ for the period of the 1950s through to the 1970s, the mean is $59 \%$ for the $1980 \mathrm{~s}$.

This is pattern is very similar for the normalization of menstrual functioning, another variable for which specific data are often not reported. Once again acknowledging these limitations, no observable change appears to have occurred over the past four decades. The mean range of normalization is $50-70 \%$ for the earlier studies while the reported mean of the more recent studies is $55 \%$. The current analysis finds, as was likewise found in the earlier review, that there was a considerable amount of missing data for eating behaviour, an area for which it is difficult to obtain information from former patients. Data pertaining to eating behaviour are even more limited than data concerning weight and menstruation. Evaluations of the normalization of eating behaviour, based on the incomplete data in the studies reviewed in our earlier paper, fluctuate from 30 to $70 \%$. The more recent studies, however, show less extreme variation. For the seven studies reporting on this issue, a mean of $44 \%$ normalization was found.

With regard to psychiatric status, the studies of the 1980 s are not methodologically superior to the earlier publications. Missing data, a lack of clear diagnostic criteria and sound assessment strategies continue to impede any viable interpretation of the data. As shown in Table 2, there is a wide pattern of psychiatric diagnoses and no indication that any disorder may be significantly related to the outcome of anorexia nervosa. At least from this limited information derived from follow-up studies there is no evidence that anorexia nervosa and affective disorders might be linked in any specific way.

Psychosocial adaptation of former anorexic patients may be evaluated by collecting data on employment, interpersonal relationships, marriage, and sexuality. The majority of studies published in the 1980s contain some information on these issues. Studies evaluating employment rates of former anorexic patients report, with few exceptions, figures close to two-thirds for 


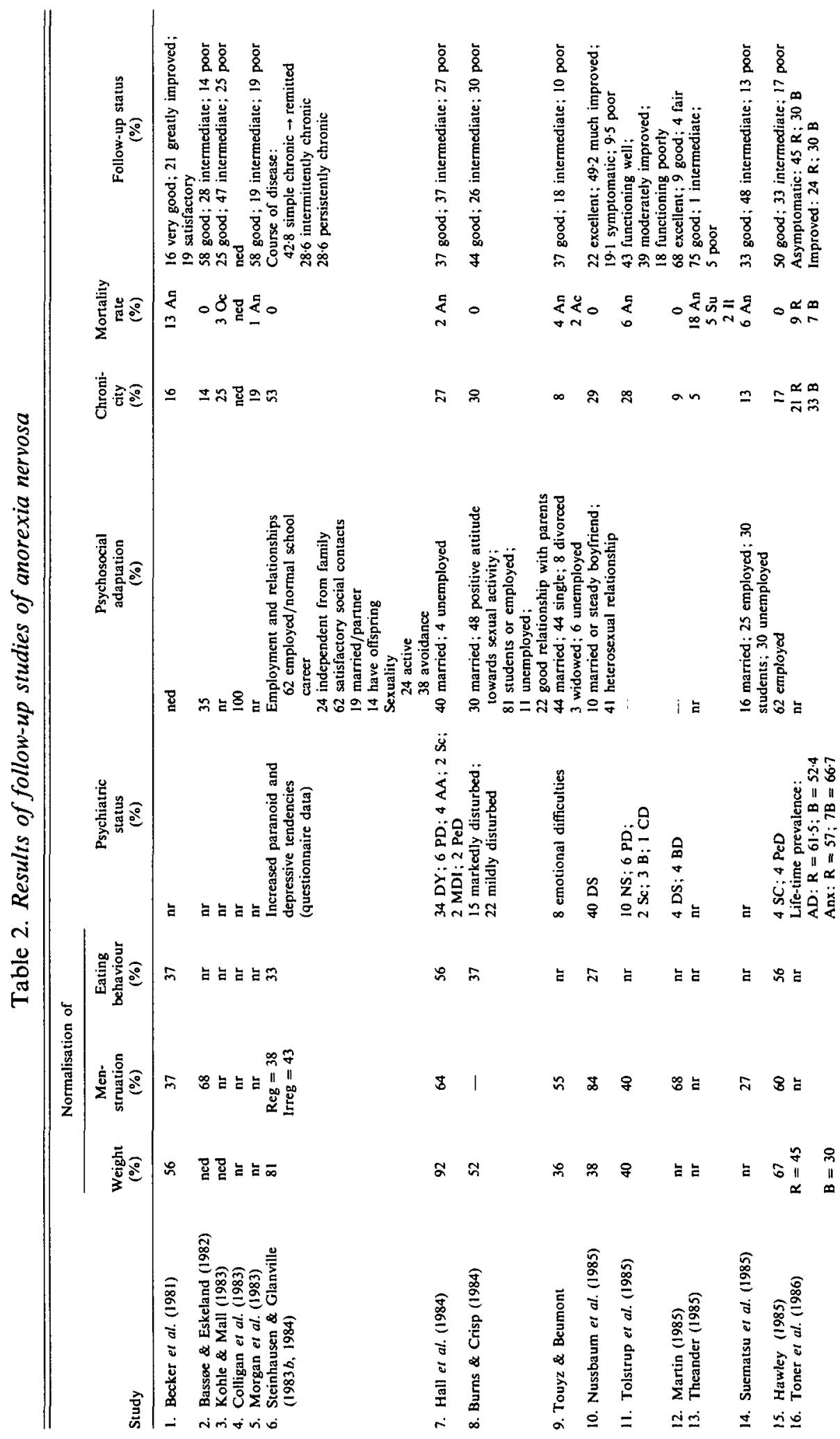



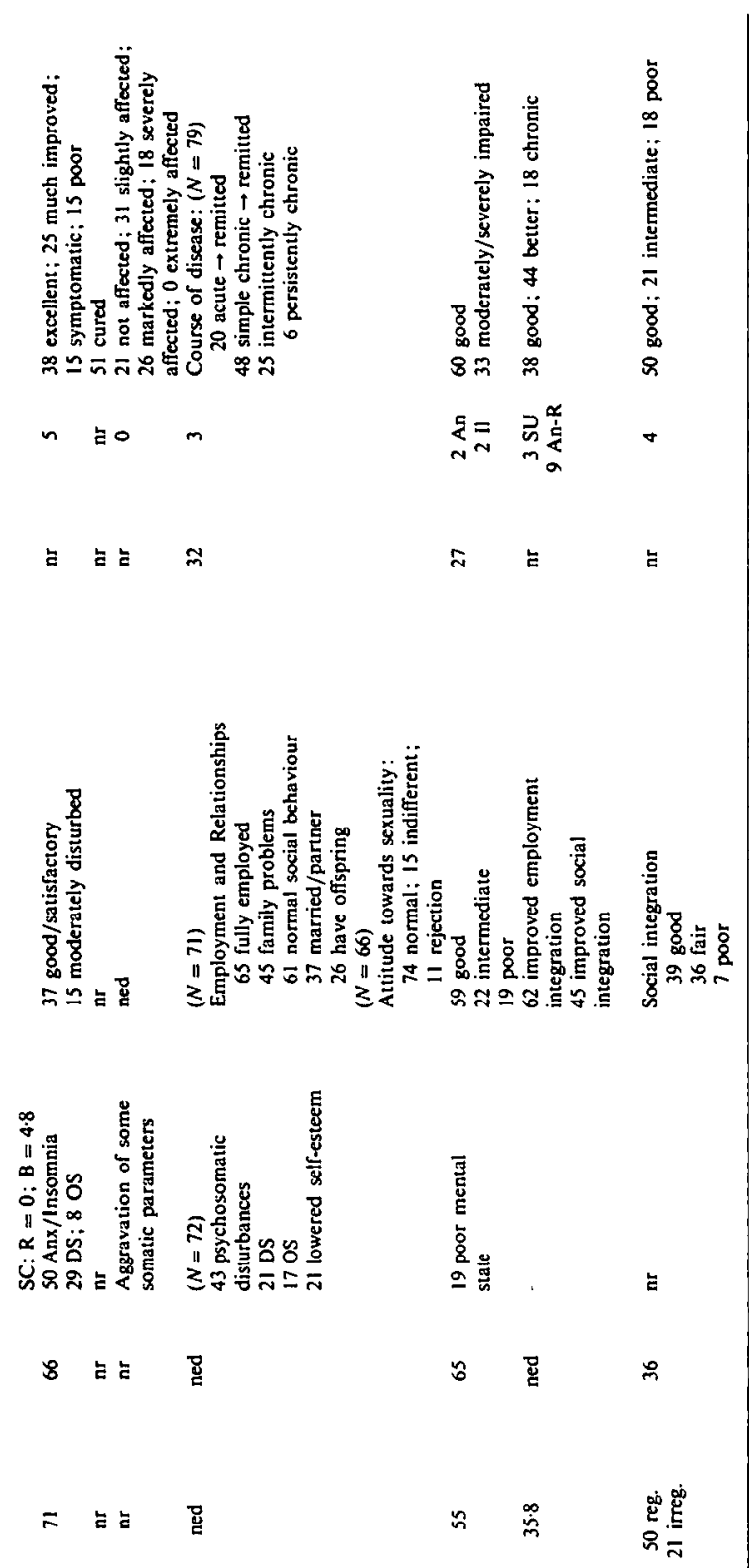

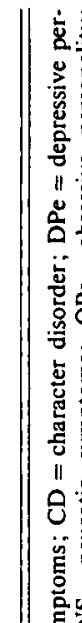
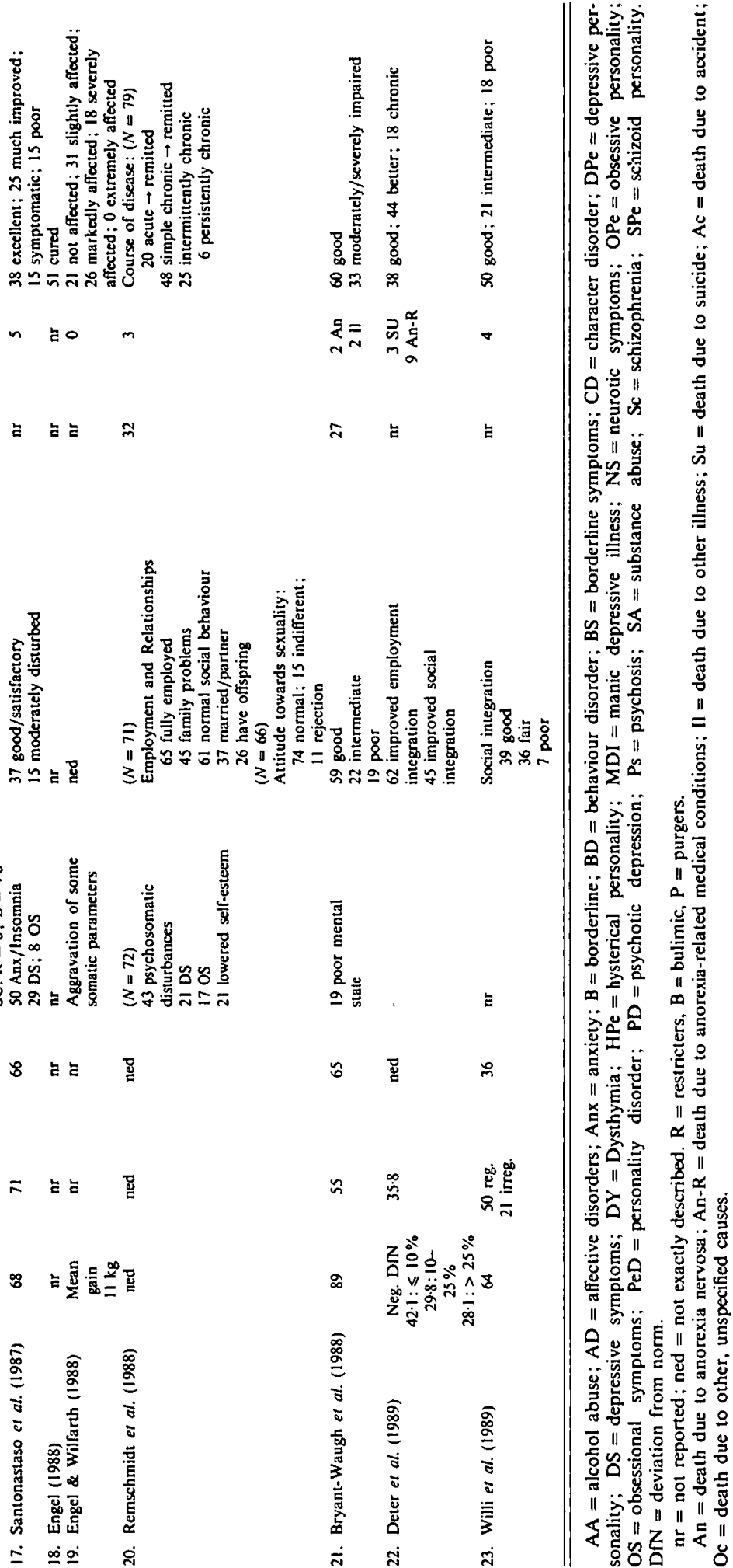

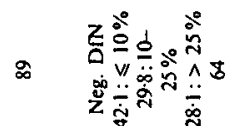

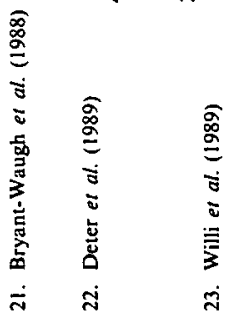

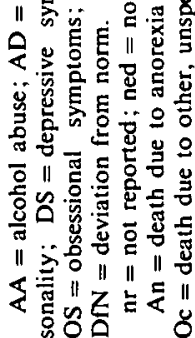


employment or normal educational career. There are very few former patients in the adult population who are married or have stable partnerships. As with most indices of psychosocial adaptation, the reported number of former patients engaging in active sexual behaviour as well as their attitude toward sexuality vary greatly from study to study. In general, psychosocial adaptation seems to be the most diverse and elusive outcome parameter to study.

In contrast, chronicity has been evaluated more easily. Although the range in the more recent studies is narrower than in the older studies, the means of the two periods are very close, namely, approximately $20 \%$. In addition, the data of the more recent studies indicate a decline in mortality rates. While the mean of the early studies was $10 \%$, it dropped to $4.4 \%$ for the 1980s. However, in none of the two series of follow-up studies has an attempt been made to standardize the data by comparing the crude mortality rate with the expected rate for that population. This deficiency makes comparison between studies with different age groups and durations of follow-up difficult. Only Patton (1988) has assessed standardized mortality rates (i.e. the ratio of observed to expected deaths) in a large series of patients. These patients had been treated between 1971 and 1981 in a tertiary referral centre for eating disorders. Where the crude mortality rate was $3 \cdot 3$, the standardized mortality rates were found to have a six-fold increase for anorexia nervosa patients.

Finally, global outcome scores for follow-up status show that, on the average, half of the subjects have a good or very good outcome while approximately $30 \%$ of the subjects have an intermediate outcome and in another $20 \%$ the scores indicate poor outcome. Due to the paucity of long-term outcome studies with more than 20 years follow-up period, evidence supporting the supposition that outcome improves with longer follow-up periods is limited. In addition, the extreme within-sample variation with regard to duration of follow-up precludes any definite conclusion.

\section{PROGNOSTIC FACTORS}

The previous review identified a number of prognostic factors which had been identified in the literature published during the 1950s to 1970s. Table 3 gives a summary based on the total of 67 outcome studies published in four decades. In the following the main prognostic factors are listed together with those studies which expand upon the information provided by the earlier review.

(a) Age of onset Three of the more recent studies (Steinhausen \& Glanville, $1983 b$; Hawley, 1985; Nussbaum et al. 1985) found age at onset to be insignificant with regard to outcome. Despite the considerable variation of data among the samples, there is still evidence, especially coming from the older studies, that an early onset of the disease is associated with favourable prognosis. (b) Hysterical personality structure In contrast to a number of older studies this factor was not identified in the study by Steinhausen \& Glanville $(1983 b)$ as being related to favourable outcome. (c) Parent-child relationships Three of the more recent studies (Morgan et al. 1983; Burns \& Crisp, 1984; Bryant-Waugh et al. 1988) support the prevailing view that good relationships between the patients and their parents are associated with good outcome.

(d) Duration of symptoms In addition to previous findings, Morgan et al. (1983), Burns \& Crisp (1984) and Hall et al. (1984) found that a short interval between onset and hospitalization or a brief episode of the illness is favourable with regard to outcome. Steinhausen \& Glanville $(1983 b)$ and Bryant-Waugh et al. (1988) did not find this to be significant for outcome. Clearly, the majority of outcome studies indicate that this variable is associated with outcome.

(e) Duration of in-patient treatment and number of re-admissions Two of the more recent studies (Steinhausen \& Glanville 1983b; Nussbaum et al. 1985) found no connection between these variables and outcome whereas two other recent studies regarded short duration of in-patient treatment (Bryant-Waugh et al. 1988; Willi et al. 1989) as prognostically favourable. Generally, there is an almost equal number of studies which regard these variables as either prognostically favourable or else as having no significance for outcome.

(f) Socio-economic status The only recent study to evaluate this variable is that of Steinhausen \& Glanville (1983b); no prognostic significance for outcome was found. The majority of older studies suggest that anorexics of higher socioeconomic status fare better. 
Table 3. A review of the prognostic factors cited during four decades of published outcome research: frequency of the identified factors (number of studies)

\begin{tabular}{|c|c|c|c|}
\hline Prognostic factor & Favourable & Unfavourable & Not significant \\
\hline Early age of onset & 10 & - & 4 \\
\hline Hysterical personality & 7 & $\ldots$ & 1 \\
\hline Conflict-free parent-child relationship & 7 & $\cdots$ & 2 \\
\hline Short interval between onset of symptoms and the beginning of therapy & 8 & - . & 2 \\
\hline Short duration of in-patient treatment/no readmissions & 6 & -. & 5 \\
\hline High social status and high level of education & 6 & $\ldots$ & 3 \\
\hline Hyperactivity and diet & $\mathbf{I}$ & - & 5 \\
\hline Vomiting & 一. & 7 & 1 \\
\hline Bulimia & - & 8 & 1 \\
\hline High loss of weight & $\cdots$ & 4 & $\ldots$ \\
\hline Chronicity/compulsivity & -- & 8 & . . \\
\hline Pre-morbid development/clinical abnormalities & - & 4 & $\ldots-$. \\
\hline
\end{tabular}

(g) Hyperactivity and dieting The studies of Steinhausen \& Glanville $(1983 b)$, Toner et al. (1986) and Bryant-Waugh et al. (1988) contribute to the growing realization that the exclusive use of these methods to reduce weight is not a significant prognostic factor.

(h) Specifically unfavourable prognostic factors Except for the study of Toner et al., the more recent studies support the earlier findings that vomiting (Nussbaum et al. 1985), purgative abuse, and bulimia are factors which are deleterious to a favourable outcome (Martin, 1985; Sohlberg et al. 1989). The same applies to extreme loss of weight and chronicity (Burns \& Crisp, 1984), as well as to pre-morbid developmental and clinical abnormalities (Morgan et al. 1983; Steinhausen \& Glanville, 1983b).

(i) Sex Sex is not an issue that was systematically evaluated in any of these studies and, therefore, no conclusions can be drawn with regard to the impact of this issue. Most of the studies included either very small numbers of males or else excluded them altogether. The only exclusively male follow-up study (Burns \& Crisp, 1984) does not indicate any differential outcome for male as compared to female patients.

\section{CONCLUSIONS}

In toto, research on the course of anorexia nervosa in the 1980 s comes up with very similar findings to those of the preceding three decades. The degree of normalization of weight, menstruation, and eating behaviour and the rates of remission and chronicity have remained quite constant over these two periods of comparison. The only significant change in data is an auspicious one - a decrease in crude mortality rates. This might indicate a growing awareness for the potentially ominous consequences of the disease. However, as mentioned above, the lack of standardized mortality rates precludes any final conclusion. Little is known about the effect of type of treatment on long-term outcome. The same applies as well to the link between anorexia nervosa and bulimia nervosa. Based on a very limited number of studies, Hsu (1988), in a recent review, summarized that

...(1) with time, twice as many restrictive anorexics develop bulimia as do bulimic anorexics changing to restrictive anorexics; (2) most bulimic anorexics retain their bulimia; (3) restrictive anorexics who develop bulimia tend to gain weight (i.e. develop normal weight bulimina nervosa), while bulimic anorexics tended to remain bulimic anorexics; (4) bulimia nervosa, normal weight or otherwise, is the commonest diagnosis after anorexia nervosa at follow-up; and (5) restrictive anorexics have a much better prognosis in terms of nutritional outcome.

Studies concerning this issue are clearly warranted.

Surprisingly, the same methodological shortcomings that flawed earlier studies, as were mentioned in the first review, continued into the last decade. With the exception of a few reports (Bassøe \& Eskeland, 1982; Steinhausen \& Glanville, 1983c; Steinhausen, 1985; Theander, 1985; Engel \& Wilfarth, 1988), there continues to be a lack of prospective studies. In a large number of the studies the assessment of psychiatric disorders and psychosocial adaptation suffer from a lack of explicit criteria, standardized interview schedules, and rating scales. These deficits are likely to affect seriously the quality of 
outcome data on psychiatric status. In general, there is also insufficient concern about withinsample variation arising from the vast differences in the duration of follow-up in many of the series.

Further limitations result from the attrition rates, which have increased in the more recent studies. While quite a number of studies have utilized a common scheme to evaluate global outcome (namely, the criteria introduced by Morgan \& Russell, 1975) further information could be accumulated by the use of more standardized procedures, i.e. interviews and questionnaires. Thus, the current conclusions are very similar to those of our previous analysis of outcome studies on anorexia nervosa and pose a challenge for research in the 1990s.

\section{REFERENCES}

American Psychiatric Association (1980). Diagnostic and Statistical Manual of Menual Disorders (DSM-III) 3rd. edn. APA: Washington, DC.

Bassoe, H. H. \& Eskeland, I. (1982). A prospective study of 133 patients with anorexia nervosa-treatment and outcome. Acta Psychiarrica Scandinavica 65, 127-133.

Becker, H., Körner, P. \& Stöffler, A. (1981). Psychodynamics and therapeutic aspects of anorexia nervosa. A study of family dynamics and prognosis. Psychotherapy and Psychosomatics 36, 8-16.

Bryant-Waugh, R., Knibbs, J., Fosson, A., Kaminski, Z. \& Lask, B. (1988). Long-term follow-up of patients with early onset anorexia nervosa. Archives of Diseases in Childhood 63, 5-9.

Burns, T. \& Crisp, A. H. (1984). Outcome of anorexia nervosa in males. British Journal of Psychiatry 145, 319-325.

Colligan, R. C., Ferdinande, R. J., Lucas, A. R. \& Duncan, J. W. (1983). A one-year follow-up study of adolescent patients hospitalized with anorexia nervosa. Journal of Developmental and Behavioral Pediatrics 4, 278-279.

Crisp, A. H. (1967). Anorexia nervosa. Hospital Medicine 1, 713-718.

Deter, H.-C., Petzold, E. \& Hehl, F.-J. (1989) Differenzierung der Langzeitwirkungen einer stationären psychosomatischen Therapie von Anorexia-nervosa-Patienten. Zeitschrift für Psychosomatische Medizin 35, 68-91.

Engel, K. (1988). Prognostic factors in anorexia nervosa. Psychotherapy and Psychosomatics, 49, 137.144.

Engel, K. \& Wilfarth, B. (1988). Therapy results and follow-up of an integrated inpatient treatment for severe cases of anorexia nervosa. Psychotherapy and Psychosomatics 50, 5-14.

Feighner, J. P., Robins, E., Guze, S. B., Woodruff, R. A., Winokur, G. \& Munoz, R. (1972). Diagnostic criteria for use in psychiatric research. Archives of General Psychialry 26, 57-63.

Hall, A., Slim, E., Hawker, F. \& Salmond, C. (1984). Anorexia nervosa - long-term outcome in 50 female patients. British Journal of Psychiatry 145, 407-413.

Hawley, R. M. (1985). The outcome of anorexia nervosa in younger subjects. British Journal of Psychiary 146, 657-660.
Hsu, L. K. G. (1988). The outcome of anorexia nervosa: a reappraisal. Psy'chological Medicine 18, 807812.

Kohle, K. \& Mall, H. (1983). Follow-up study of 36 anorexia nervosa patients treated on an integrated internistic-psychosomatic ward. International Journal of Eating Disorders 2, 215219.

Martin, F. E. (1985). The treatment and outcome of anorexia nervosa in adolescents: a prospective study and five-year followup. Journal of Psychiatric Research 19, 509 514.

Morgan, H. G., Purgold, J. \& Welbourne, J. (1983). Management and outcome in anorexia nervosa a standardized prognostic study. British Journal of Psychiatry 143, $282-287$.

Morgan, H. G. \& Russell, G. F. M. (1975). Value of family background and clinical features as predictors of long-term outcome in anorexia nervosa: four-year follow-up study of 41 patients. Psychological Medicine 5, 355 371.

Nussbaum, M., Shenker, I. R., Baird, D. \& Saravay, S. (1985). Follow-up investigation in patients with anorexia nervosa. Journal of Pediatrics 106, 835-840.

Patton, G. C. (1988). Mortality in eating disorders. Psychological Medicine 18, 947951.

Remschmidt, H., Wienand, F. \& Wewetzer, C. (1988). Der Langzeitverlauf der Anorexia nervosa. Monatsschrift für Kinderheilkunde 136, 726-731.

Russell. G. F. M. (1970). Anorexia nervosa: its identity as an illness and its treatment. In Modern Trends in Psychological Mcdicine' (ed. H. Price), pp. 131-164. Butterworth: London.

Santonastaso, P., Favaretto, G. \& Canton, G. (1987). Anorexia nervosa in Italy: clinical features and outcome in a long-term follow-up study. Psychopathology 20, 8 . 17.

Sohlberg, S., Norring, C., Holmaren, S. \& Rosmark, B. (1989). Impulsivity and long-term prognosis of psychiatric patients with anorexia nervosa/bulimia nervosa. Journal of Nervous and Mental Disease $177,249258$.

Steinhausen, H.-C. (1985). Evaluation of in-patient treatment of adolescent anorexic patients. Journal of Psychiatric Reseurch 19, 371-375.

Steinhausen, H.-C. \& Glanville, K. (1983a). Follow-up studies of anorexia nervosa a review of research findings. Psychological Medicine 3, 239249.

Steinhausen, H.-C. \& Glanville, K. (1983h). A long-term follow-up of adolescent anorexia nervosa. Acta Psychiatrica Scandinarica 68 , $1-10$.

Steinhausen, H.-C. \& Glanville, K. (1983c). Retrospective and prospective follow-up studies in anorexia nervosa. International Journal of Eating Disorders 2, 221 235.

Steinhausen, H.-C. \& Glanville, K. (1984). Der langfristige Verlauf der Anorexia nervosa. Nervenarzt 55, 236248.

Suematsu, H., Kuboki, T. \& Itoh, T. (1985). Statistical studies on the prognosis of anorexia nervosa. Psychotherapy and Psychosomatics 43, $104-112$.

Theander, S. (1985). Outcome and prognosis in anorexia nervosa and bulimia: some results of previous investigations, compared with those of a Swedish long-term study. Journal of Psychiatric Research 19, 493-508.

Tolstrup, K., Brinch, M., Isager, T., Nielsen, S., Nystrup, J., Severin, B. \& Olesen, N. S. (1985). Long-term outcome of 151 cases of anorexia nervosa. Acta Psychiatrica Scandinavica 71, 380387.

Toner, B. B., Garfield, P. E. \& Garner, D. M. (1986). Long-term follow-up of anorexia nervosa. Psychosomatic Medicine 48, 520-529.

Touyz, S. W. \& Beumont, P. J. V. (1984). Anorexia nervosa. A follow-up investigation. Medical Journal of Ausiralia 141, 219222.

Willi, J., Limacher, B. \& Nussbaum, P. (1989). ZehnjahresKatamnese der 1973.75 im Kanton Zürich erstmals hospitalisierten Anorexien. Schweizerische Medizinische Wochenschrift 119, 147 159. 